\title{
DESPRE FUNCT⿱ONALITATEA POETICO-STILISTICĂ A STRUCTURII ADVERSATIVE ÎN CÂTEVA POEME ALE LUI LUCIAN BLAGA
}

\author{
Emanuel Lupașcu-Doboș \\ e.1upascu99@yahoo.com \\ Universitatea „Babeș-Bolyai”, Cluj-Napoca
}

\begin{abstract}
This paper starts from the theoretical support of some central figures in the field of study of Lucian Blaga's works: Mircea Borcilă and Mircea Scarlat. The first outlook that this essay will focus on the linguist and poetician from Cluj, Mircea Borcilă, with his esteemed article from 1987 (Contribuții la elaborarea unei tipologii a textelor poetice). The other perspective is that of Mircea Scarlat, from The History of Romanian Poetry (vol. III). In the articulation of Blaga's poetics, the exegete finds important the adversative structure as strategies of establishing the poetic tension and polarization of the world newly created. Thus, the purpose of this essay is to emphasize / demonstrate the fact that the poetic finality of the creation of worlds motivates even the linguistic structures, and the poetic meaning is vertebrated by, but also beyond the linguistic "material". These mechanisms of meaning articulation through and beyond language will be followed in the poems as "Flori de mac" (from the volume Pașii profetului), "Paradis in destrămare" (from the volume Laudă somnului) and "Isus și Magdalena" from the Lucian Blaga's unpublished poems .
\end{abstract}

Keywords: poetics, adversative structures, articulation of meaning, dialectics, metaphor, polarities

\section{Considerații generale:}

1. Lucrarea de faţă are ca scop investigarea structurilor adversative în textele poetice ale lui Lucian Blaga și, prin extensie, articularea sensului poetic în funcție de, dar și dincolo de structurile lingvistice. În vederea acestui demers, vom re-valorifica/valida construcțiile teoretice a două personalități de o valoare incontestabilă pentru promovarea și cercetarea operelor blagiene: Mircea Borcilă și Mircea Scarlat. Astfel, din punct de vedere metodologic, vom sublinia aspecte importante ale textelor celor doi autori, aparat științific pe baza căruia vom realiza o analiză poetico-stilistică a trei poezii exponențiale pentru cercetarea noastră.

1.1. Articolul lui Mircea Borcilă din 1987, Contribuţii la elaborarea unei tipologii a textelor poetice, cristalizează o teorie coerentă despre modalitățile articulării sensului în textele poetice, precum și un set de criterii de tipologizare a acestora, plecând de la teorii recente - pentru acea vreme - ale poeticii, ale semanticii structurale și culturale și ale metaforologiei. Având ca 
„,nucleu” distincția blagiană dintre metafora lingvistică și cea culturală (Blaga 349) și concentrându-și atenția asupra fenomenului de ,poesis discursiv” (Borcilă 186), poeticianul clujean face ,posibilă definirea unui prim set de criterii de tipologizare, cu ajutorul căruia să se poată opera disocierea unor categorii funcțional-tipologice fundamentale în domeniul textelor poetice" (188). Construcția teoretică sistematică și solidă propune două tipuri metaforice de funcționare a textelor poetice, ca produse culturale:

a) tipul metaforic ,expresiv”/,,plasticizant” (A), cu o finalitate ,plasticizantă”, care nu îmbogățește sensurile lumii fenomenale, ci lărgește domeniul de cuprindere al „,sensibilității” umane ( 189). Principiul axiologic-existențial care vertebrează acest tip metaforic este - calchiind după semantica lotmaniană - unul „sintactic”, care mizează pe o viziune poetică de tip aditiv (,concatenare” a imaginilor poetice). Această expresie preferată de avangardiști și de Tudor Arghezi livrează, în definitiv, un mod de construcție ,diagramatic” ( 190);

b) tipul metaforic „revelator” (B), înglobând o finalitate „revelatorie”, adică de îmbogăţire a sensului lumii fenomenale, care propune revirimentul unei lumi numenale, conectată cu Universul Empiric prin obiecte-,,căi de acces” (189). Fondat pe un principiu axiologic-existenţial „semantic”, acest proces metaforic aduce achiziții în planul ontologic al ființei umane, extinzând ad infinitum ,orizontul de mister”. Poeți precum Ion Barbu și Lucian Blaga reclamă acest regim poetic cu un centru de construcție „simbolic” ( 191).

Coroborând reperele teoretice ale lui Mircea Borcilă cu aspectele lingvisticii textului ale lui Eugen Coșeriu, putem ajunge la concluziile parțiale conform cărora modurile de instituire a sensului în poezie, prin organizarea sa interioară, își au rădăcinile primare în limbaj, adică în „plenitudinea funcțională” a limbajului (Coșeriu apud Boc 227). Astfel, finalitatea textului poetic este creația de lumi, lumi substanțial diferite de lumea cunoscută prin experiență, lumi menite să transfigureze și să transgreseze limitele ontologice prin și dincolo de limbaj.

1.2. Cu un „nucleu” teoretic asemănător domeniului lingvistic (acela al considerării limbajului ca „instrument” al construcției de lumi), capitolul din Istoria poeziei românești (III) interpretează opera poetică blagiană prin comentarea ei din optica sintaxei textuale, pentru că „,analiza sintactică e relevantă în cazul de față” (Scarlat 244). Pornind de la Eu nu strivesc corola de minuni a lumii, Mircea Scarlat identifică ocurența deosebită a două structuri adversative (,,nu 
A, ci B” și „A, dar B”) în construcția sintactică a poemului. Imaginarul poetic debutează printr-o „afirmație prin negație”, versului „Eu nu strivesc corola de minuni a lumii/ și nu ucid/ cu mintea tainele, ce le-ntâlnesc/ în calea mea” opunându-i-se ,eu cu lumina mea sporesc a lumii taină - ” (Blaga 19). În continuare, polarizarea eu-alteritate (Scarlat 245) este circumscrisă versurilor aflate în raport adversativ: „Lumina altora/ sugrumă vraja nepătrunsului ascuns/ în adâncimi de întuneric,/ dar eu,/ eu cu lumina mea sporesc a lumii taină - ” (s.m. - E.L.). În fine, amplificarea metaforic-comparativă a astrului selenar se datorează unei negări a unui set de valori: ,şi-ntocmai cum cu razele ei albe luna/ nu micșorează, ci tremurătoare/ mărește și mai tare taina nopții” (s.m. - E.L.).

Fenomenul constituțiilor textuale pe fundamentul unor scheme adversative nu este o constantă întâlnită numai în poeziile lui Lucian Blaga, ci și în textele sale filosofice ori epice. Scarlat amintește de un exemplu din Pietre pentru templul meu, afirmând că ,structura din poemul comentat apare și în exprimarea aforistică a aceleiași idei: «datoria noastră în fața unui adevărat mister nu e să-1 lămurim, ci să-l adâncim așa de mult, încât să-1 prefacem într-un mister și mai mare»»" (Scarlat 246). Considerăm că această idee poate fi susţinută şi prin alte exemple. În acest sens oferim, drept eșantion, alte patru exemple ale uzitării construcției adversative, prin trei excerpte din cele trei Trilogii, iar unul din Luntrea lui Caron:

1. Într-o metaforă revelatorie nu interesează aşadar numai analogia dintre «a» şi «b», ci și dizanalogia, care e tocmai destinată să completeze debordant pe «a» (s.m. E.L.) (Blaga 2018a, 393).

2. Considerații de cu totul altă natură, care nu țin nici de teoria cunoașterii, nici de logică, $c i$ de filozofia culturii sau de filozofia istoriei, ne fac să credem că însuși ritmul istoric ne duce spre afirmarea ecstaziei intelectuale ca fel posibil de a gândi pentru o întreagă epocă (s.m. - E.L.) (Blaga 2013, 235).

3. Teoria stilului am dezvoltat-o sistematic, permiţ̧îndu-i ramificări nevisate pînă aici, şi asimilînd teritorii ce nu aparţin numai psihologiei sau esteticii, sau unei anume filozofii descriptive a culturii, $c i$ antropologiei, ontologiei şi metafizicii (s.m. - E.L.) (Blaga 1996, 8).

4. Intenția mea era să dau poezie care să nu pară traducere, ci să fie poezie. (s.m. E.L.) (Blaga 2006, 78). 
Revenind în spațiul realizării sensului poetic, Mircea Scarlat vede în tiparul adversativ al poemelor lui Lucian Blaga o constantă poetică: el ar institui, pe de o parte, o ,tensiune emoțională” și, pe de altă parte, o ,alternativă a rezolvării tensiunii” (Scarlat 246). Ocurența acestei „organizări” ideatice și în textele filosofice ale lui Blaga, precum și relevarea acestora în studiile lui Mircea Borcilă validează o consistență a etapizării organice a ,operațiilor semantice de articulare a sensului poetic: diaforică, endoforică, epiforică” (Terian 328). În această „dinamică metaforică a instituirii sensului” (Boc 232), se urmărește, etapizat, a) prezentarea a două Câmpuri Referențiale (CR) aflate într-o tensiune ireconciliabilă, b) ,scurtcircuitarea” acestei tensiuni, grație analogiei, printr-un semantism comun, „scurtcircuitare” realizabilă, fie prin b1) glisarea unui CR către celălalt, fie prin b2) elaborarea unui plan „meta-textual”, care transcende cele două CR, și c) instituirea unui Câmp Referențial Terț (CR III), în care ,împăcarea celor două planuri ar fi posibilă” (Mircea Borcilă apud Terian 328).

2. Având în vedere coordonatele teoretice precizate anterior, vom încerca, în continuare, să remarcăm, în trei poeme ale lui Lucian Blaga (Flori de mac, Paradis în destrămare și Isus și Magdalena), felul în care organizările sintactice adversative contribuie substanțial la procesul dinamic metaforic, precum și soluţiile poetice pentru aceste „dizarmonii”.

2.1. Flori de mac este construită pe șablonul schemei adversative atât de utilizată de Blaga, însă nu după modelul „,nu A, ci B”, ci după un altul „A, dar B”, care „,marchează contrazicerea aşteptărilor declanşate de primul termen al raportului sintactic adversativ” (GALR 643):

Aș vrea să vă culeg în brațe feciorelnicul avânt, dar vi-e atât de fragedă podoaba, că nu-drăznesc, o, nici la pieptul gândurilor mele să vă strâng. (s.m. - E.L.) (Blaga 2018b, 79)

Poezia se constituie drept un monolog adresat, o comuniune discursivă între eul liric și florile de mac, motiv al contemplației artistice într-un fundal agrest (,cum vă privesc pe malul mării de secară”). Imaginarul este construit, la nivel gramatical, pe opoziția dintre modul indicativ, timpul prezent, un timp factual, al tribulațiilor ființei umane („fluier”, ,,pătrunde”, „,privesc” etc.) și modul condițional optativ, tot timpul prezent, al virtualității intenției poetului (strofele a doua, a treia, a patra și a cincea au ca centru verbal construcția ,aș vrea”, urmată de o completivă directă 
- „să vă cuprind”, „să vă culeg”, „să vă strivesc”). Nivelul volițional al poetului este dominat de un imaginar violent - „să cuprind”, „să culeg”, „,s̆ strivesc” -, corespondent al unei atitudini „paradisiace”, dacă ar fi să folosim distincția cunoașterii blagiene ,,paradisiac”/,luciferic”. Acestui registru afectiv agresiv i se opune registrul delicat, tandru și fragil al floralului, năzuința eului poetic fiind blocată de ,frăgezimea podoabei” macului.

$\mathrm{Cu}$ toate că spectrul floral beneficiază de o interpretare grațioasă, încă din prima strofă acesta capătă și o latură thanatică: surprinderea florilor de mac generează în sufletul poetului o „teamă de moarte”. Ioana Em. Petrescu relevă motivele acestui ,incident” poetic: a) culoarea macului este asociată cu ,înflăcăratul amurg de vară”, adică cu o imagine progresivă a evanescenței luminii; b) friabilitatea florii evocă melancolia lipsei rezistenței în timp a materiei, ergo a ființei umane; c) există un izomorfism cromatic între mac și sângele asudat de Christos pe muntele măslinilor, sinonim cu ,agonia divinului”, activând, astfel, „gândirea mitică” a ocularului descriptiv (Petrescu 95). Pornind chiar de la această poezie, Ioana Em. Petrescu identifică o constantă a liricii blagiene: ,imaginarul cenușă-polen al morții” ( 94), în acest poem născându-se o „legendă a macului” după Lucian Blaga. Simplificând teoria, viața (fie ea de ordin mineral, vegetal, animal ori uman) își conține ,germenii” morții, ca singură certitudine gnoseologică. Or, această viziune existențialistă se repetă la diferiţi filosofi și gânditori ai secolului al XX-lea (v. Martin Heidegger, Edmund Husserl, Jean-Paul Sartre etc.).

Operatorul adversativ „dar” contrastează, în acest sens, nu numai perechea ,agresivfragil”, ci și ,viaţă-moarte”. Odată cu această viziune inedită, antinomiile se aneantizează și devin termeni ai unei dialectici organice. Forând mai adânc în articulaţiile intime ale poemului şi întorcându-ne la procesul de poesis discursiv, se poate identifica metafora „revelatorie” „floarea de mac-sângele Mântuitorului”. Pentru tipul metaforic „revelator”, schemă poetică după care este construită și poezia Flori de mac, principiul axiologic-existențial „semantic” „se bazează pe presupoziţia că anumite fenomene reperabile în planul designaţional al lumii date posedă o semnificație prin ele însele, i.e. înainte și în afara procesului de construcție a sensului [...]” (Borcilă 1987, 189). Potrivit acestui principiu descris de Mircea Borcilă, există lexeme ,privilegiate” poetic, adică sunt încărcate, așa cum o numește Blaga, cu o „sarcină mitică” (Blaga 2018a, 381). Așadar, „sarcina mitică” a cuantei referențiale „floare de mac - sânge” este identificabilă în tezaurul mitologic al matricei stilistice românești, întrucât ,în tradiția mito-poetică [macul] e legat de somn şi de moarte” (Evseev 107). În Legendele florei, Tony Brill colecționează nu mai puţin de patru 
legende ale macului culese din diferite zone ale țării (163-176). Cea mai relevantă în contextul poemului blagian ni se pare legenda care înglobează calvarul christic: într-o poveste în care flora este cvasi-antropomorfizată (florile sunt înzestrate cu „darul” vorbirii), macul este o floare cu o morfologie de „cupă”, inițial de culoare albă. În drumul său spre Golgota, flagelat și batjocorit de mulțimea care-1 osândește la moarte, Isus se apleacă asupra acestor flori, le sărută, sângele prelingându-se de pe fața sa în „cupa” macilor. Adresarea ni se pare memorabilă și o reproducem ca atare:

- De-acum înainte să fii roșie ca sângele pe care-1 porți în cupa florilor tale și ani după ani, să înviorezi cu roșul petalelor tale, covorul câmpiilor după tot pământul, purtând în culoarea lor, mărturia suferinței mele. (Brill 1994, 176)

$\mathrm{Nu}$ putem afirma cu exactitate dacă Lucian Blaga cunoștea această specifică legendă a macului, însă putem specula asupra acestui fapt, considerând selecția privilegiată a florii de mac, la nivel prototextual, ca fiind nearbitrară. Imaginea macului asimilează o ,viziune mitică” și o „geografie mitică” ancestrală și este, așa cum îl numește Mircea Borcilă, un „«punct» sau «cale» de acces («punți de salt») spre planul ontologic secund” (Borcilă 190). Realizarea „saltului semantic”, prin „,anularea sensului obișnuit al faptelor, substituindu-li-se o nouă semnificație” (Borcilă 37), îndepărtează definirea ireductibilă a aspectului botanic, pur biologic al florilor de mac și le transpune într-un orizont numenal, printr-un factor ,analogic-dizanalogic”: ea este purtătoarea suferinței Mântuitorului și, deci, a thanaticului (element determinant al sentimentului de angoasă ce ,încolțește” în sufletul poetului).

2.2. Una dintre poeziile etalon ale liricii lui Blaga, Paradis în destrămare, uzitează, la rândul ei, structura adversativă, care construiește un alt set de opoziții. Tectonica poemului respectă o viziune mitică prestabilită, situând imaginarul poetic sub incidenţa sacrului:

Portarul înaripat mai ține întins

un cotor de spadă fără de flăcări.

Nu se luptă cu nimeni, dar se simte învins. (s.m. - E.L.) (Blaga 2018b, 138)

Funcționalitatea operatorul poetic adversativ este aceea de a introduce un factor „surpriză”, de a înșela expectanţele cititorilor: fiindcă este lipsit de activitate („nu se luptă cu nimeni”), ar fi absurd ca forțele îngerului să fie secate. Cu toate acestea, el „se simte învins”. Hipotextul acestei poezii este reprezentat de secvența biblică din cartea Facerii, corespunzând 
surghiunirii din rai a protopărinților Adam și Eva. „Paradis în destrămare” nu este doar o metaforă „revelatorie” pentru societatea modernă aflată în plin proces entropic, cauzat de „surghiunirea” sacrului, printr-o exacerbare a cunoașterii ,paradisiace”, ci este și o metaforă a incompletitudinii divinului în lipsa umanului. Opera perfectă a lui Dumnezeu se „fisurează” odată cu izgonirea din rai a omului, el reprezentând piesa fundamentală a creației divine. Descuamarea întregului univers este resimţită în întreaga sa arhitectură: oamenii își pierd divinitatea, iar creația divină (i.e. îngerii), paradoxal, își câștigă umanitatea. „Umanizarea” angelicului se reproduce, simetric, pe scară ierarhică: primii afectați sunt heruvimii, cei care țin „un cotor de spadă fără de flăcări” (conform imaginarului biblic, aceștia păzesc drumul către grădina Edenului, învârtind săbii de foc), serafimilor „cu părul nins” li se refuză adevărul comprehensibil, deși acced către el: „serafimi cu părul nins/ însetează după adevăr,/ dar apele din fântâni/ refuză gălețile lor” (s.m. - E.L.) (Blaga 2018b, 138). Ascensiunea inerentă făpturilor sacre devine acum prohibită, anabasisul convertinduse într-un catabasis: „,arhanghelii se plâng/ de greutatea aripelor” (138). „Inversarea” (imaginea barocă a lumii pe dos), sugerată de construcția sintactică adversativă, este reluată imaginativ de ipostaza Duhului Sfânt care, de data aceasta, nu mai furnizează limbile de foc, ci „,cu pliscul stinge cele din urmă lumini” (138). Drama izgonirii adamice este, de fapt, și drama divinității (sau a întregului regn divin), iar textualizările acestui mundus inversus validează teza conform căreia Paradis în destrămare ar fi un ,«contra-mit» poetic al paradisului tragic” (Colțun 144). Raţiunea Edenului era însuși omul, spațiul paradisiac era construit pentru om, iar în lipsa acestuia își pierde finalitatea.

Prin urmare, o „traducere” a poeziei Paradis în destrămare în parametrii teoriei cuantelor referențiale (cr) și a Câmpurilor Referențiale ( $v$. Terian ) va potența o nouă elucidare a operațiilor semantice de anulare a tensiunii dintre termenii antinomici: soluția trecerii într-un plan „metatextual”. Acest plan care trece dincolo de înțelesurile obișnuite ale textului este posibil mulțumită instituirii Câmpului Referențial Terț (CR III), care face realizabilă conjuncția dintre CR I (planul divinităţii, reprezentat, aici, prin regnul angelic) și CR II (planul umanităţii, construit aluziv în text, prin antropomorfizarea cetelor îngerești). Dacă mitologia-,,nucleu” a religiei creștine nu recunoaște atributele umane ale angelicului, noua lume poetică blagiană nu numai că elaborează un întreg context al „coborârii” divinului în empiric, ci și climatul unui sistem metafizic în care și divinitatea se ,îmbolnăvește” în lipsa Omului. 
Încă o dată, Blaga nu încearcă să „,sugrume vraja nepătrunsului ascuns”, ci oferă un plus de sens acesteia. Justificarea unei asemenea metafore ,revelatorii” extinse la două paliere (insuficiența omului fără divinitate și carența divinului fără uman) își are rădăcina în credința poetului de a re-ordona miturile fondatoare ale lumii, îmbogățindu-le ,orizontul de mister” (Borcilă 37). Amplificând substanțial universul ,secund” - i.e. lumea numenală - cu semnificații noi și inedite, textul își exercită par excellence funcția sa de creație de lumi. Universul de Discurs Poetic instaurează noi coordonate ontologice unde Divinitatea este ea însăși incompletă în lipsa Omului, aidoma înstrăinării umanului de sacralitate.

2.3. Un caz simptomatic pentru funcționalitatea poetico-stilistică a structurii adversative este cel al poeziei Isus și Magdalena, poezie scrisă simultan celor din volumul Poemele luminii, însă neinclusă de poet în edițiile definitive. Centrul adversativ al acestei poezii îl constituie conjuncția totuşi (sinonimă parțial cu dar, însă cu același rol pragmatico-discursiv):

Isus grăbea spre sat și gândul îi zbura aiurea:

„În ochii ei era numai păcat

Şi numai crimă

Era în mâna ei și-n strângerea-i fierbinte -

Şi totuși, nu-nțeleg, o rază ce-i juca-n privire

Striga și orbitoare mă chema:

Şi-n mine-i Dumnezeu!...” (s.m. - E.L.) (Blaga 2018b, 562)

Poezia, aidoma celor analizate anterior, dezvoltă, de asemenea, un filon religios: este dezvoltată metatextual, cel mai probabil, scena ulterioară exorcizării Mariei Magdalena, căci „Isus grăbea spre sat” (Luca 8:1-3, Marcu 16:9, Ioan 20:1 \& Matei 27:56). În urma acestui eveniment, Mântuitorul este devorat spiritual de lumina din ochii posedatei, lumină care „striga și orbitoare mă chema:/ Și-n mine-i Dumnezeu!...”. Astfel că, în ciuda faptului că femeia era cuprinsă de ,întunericul” demonic, în adâncul sufletului ei exista încă embrionul luminii și nu ai unei lumini oarecare, ci a Luminii lui Dumnezeu (fascicule de lumină din Fiat lux!). Evident, construcția adversativă coagulează cele două Câmpuri Referențiale (CR): CR I, constituit de seria semantică „frumos-divin-bine-lumină” și CR II, alcătuit din seria lexemelor „urât-demonic-rău-întuneric”.

Elementul de noutate poetică, în raport cu suportul textual biblic, este marcat de către siderarea Mântuitorului la aflarea unui fascicul de lumină dumnezeiască. Punctul de fugă ar 
fi reprezentat, astfel, de către existența unui element din CR I în mijlocul CR II. Misterul acesta, care reprezintă un „mister” chiar și pentru Isus Christos, este susținut și augmentat prin intermediul „revelației” Mântuitorului din strofa următoare:

Isus grăbea spre sat și soarele spre-apus...

Isus visa -

Şi ochii-i s-au oprit o clipă

Pe luciul

Mocirlelor ce ascundeau în trestie Iordanul...

O undă de blândețe-i înecă deodată fața:

„O, soarele, divinul, te orbește cu lumina-i

Şi-atuncea chiar când se răsfrânge în noroi...." (Blaga 2018b, 562)

Se poate lesne observa cum se cristalizează aceeaşi polaritate între CR I și CR II pusă acum în slujba unei singure sintagme ,luciul mocirlelor”. Dacă în prima strofă exista o diferență fundamentală între figura masculină a divinității și cea feminină a păcatului, în ultima strofă, câmpurile semantice disparate sunt reunite până la amalgamare într-un întreg, menit să cuprindă atât principiul „frumosului”, cât și pe cel al „urâtului”. Din nou, tensiunea termenilor contrari/antinomici este desființată prin trecerea unui CR la celălalt, deci printr-o dialectică. Grație intuiţiei poetice și filosofice, sunt reconciliate principiul binelui și cel al răului, prin supoziţia că există, în ciuda aparențelor, o virtualitate pozitivă (chiar dacă era posedată de șapte demoni, chipul Magdalenei oglindea încă „chipul și asemănarea lui Dumnezeu”). Astfel, tensiunea de ordin simbolic, cea care lucrează în domeniul miturilor religioase, operează și la nivel plastic, odată ce Isus face analogia luminii din ochii întunecați ai Magdalenei cu reflexia soarelui în cercurile concentrice ale mocirlelor. Însă motivarea plastică a poeziei face ca imaginea „mocirlelor” să devină acel ,punct de acces”, acea „,zonă privilegiată” a universului fenomenal/empiric prin care se „strecoară” substanța misterului transcendental (din universul „esențelor”).

Construcția metaforei ,revelatoare” se păstrează aproape ca în textul din Flori de mac: existența a două câmpuri referențiale I și II, dintre care unul este, de fapt, un obiect „privilegiat” mitopoetic și care îl conține pe celălalt, revelare ce suspendă, temporar, tensiunea dintre ele. Diferența specifică a acestui text este sensul, direcția Câmpurilor Referențiale: a) pentru Flori de mac translația se realizează dinspre florile de mac, înspre sângele Mântuitorului (mac $\rightarrow$ sânge), realizând metafora ,revelatoare” a „florilor de mac-sângeleui christic”; în timp ce b) în Isus și Magdalena glisarea se face dinspre lumina ochilor Mariei Magdalena, înspre lucirea mocirlelor din 
apa Iordanului (lumina $\rightarrow$ lucire; Magdalena $\rightarrow$ mocirla Iordanului), făcând ca metafora „revelatorie” să se coaguleze prin exercitarea a două funcții ecuaționale - i.e. de identificare (Borcilă 36).

\section{Concluzii}

Așa cum am putut observa, organizarea discursivă în funcție de un centru conjuncțional adversativ polarizează, după principiul axiologic-existențial semantic, două principii care, inițial, par a fi în perfectă antiteză sau fără a conține elemente izomorfe. Polii opuși existenţiali (momentul diaforic) pot fi reprezentați de cuplul viaţă-moarte, cenuşă-polen, umanitate-divinitate, fecunditatesterilitate, violență-fragilitate, frumos-urât, bun-rău, lumină-întuneric etc. Tensiunea dintre cele două elemente antinomice este atenuată (momentul endoforic), schematic, fie prin glisarea unui termen spre celălalt, i.e. distrugerea antinomiilor prin instituirea dialecticii - este cazul poeziilor Flori de mac și Isus și Magdalena -, fie prin construcția poetică a unei noi lumi (ori Câmp Referențial Terț), în care concilierea termenilor era posibilă (momentul epiforic), adică printr-o construcție „meta-textuală” (Mircea Borcilă apud Terian 328) - cazul poeziei Paradis în destrămare. Acordul privilegiat al structurilor adversative poartă amprenta eului liric, limbajul fiind „materialul” care ordonează universul de discurs poetic, constituit pe fundamentul unei transsemnificări a ierarhiilor ontologice, iar articularea unui „,nou univers” se realizează prin și dincolo de ,ansamblul” limbajului la toate palierele posibile (morfosintactic, lexico-semantic ori pragmatico-discursiv).

\section{Bibliografie:}

Academia Română. Gramatica limbii române. I Cuvântul. București: Editura Academiei, $2005 / 2008$.

Blaga, Lucian. Trilogia Valorilor, vol. I, București: Humanitas, 1996.

Blaga, Lucian. Luntrea lui Caron. București: Humanitas, 2006.

Blaga, Lucian. Trilogia cunoaşterii. București: Humanitas, 2013

Blaga, Lucian. "Geneza metaforei și sensul culturii”, în Trilogia culturii, 331-500. București: Humanitas, 2018a. 
Blaga, Lucian. Opera poetică. ed. îngrijită de George Gană și Dorli Blaga. București: Humanitas, $2018 b$.

Boc, Oana. "Metafora și instituirea sensului poetic. O privire dinspre și înspre Blaga", în QVAESTIONES ROMANICAE VIII Interferențe și contraste în Romania VIII (1), 2020, pp. 226235 ,.

Borcilă, Mircea. "Contribuții la elaborarea unei tipologii a textelor poetice”, în Studii și cercetări lingvistice XXXVIII (3), 1987, pp 185-196.

Borcilă, Mircea. "Contribuții la definirea tipului poetic al textelor lui Blaga", în Cercetări de lingvistică XXXVII (2), 1992, pp. 133-141.

Borcilă, Mircea. "Teoria blagiană a metaforicii «nucleare»”, în Steaua XLIV (8-9), 1993, p. 59.

Borcilă, Mircea. "Bazele metaforicii în gândirea lui Lucian Blaga", în Limbă și literatură XLI, 1996, pp. 28-39.

Brill, Tony. Legendele florei. București: Editura „Grai și Suflet” - Cultura Națională, 1994.

Colțun, Gheorghe. "Motive biblice în poezia blagiană", în Receptarea Sfintei Scripturi: între filologie, hermeneutică şi traductologie. Lucrările Simpozionului Naţional „Explorări în tradiţia biblică românească şi europeană ” III, 2014, pp. 143-150.

Evseev, Ivan. Dicționar de simboluri și arhetipuri culturale. Timișoara: Amarcord, 2001.

Petrescu, Ioana E. Eminescu și mutațiile poeziei românești. Cluj-Napoca: Dacia, 1989.

Scarlat, Mircea. Istoria poeziei românești. Vol. III. București: Minerva, 1986.

Terian, Simina. "Premise pentru o poetică a textemelor", în The Proceedings of the "European Integration - Between Tradition and Modernity” Congress, nr. 5, 2013, pp 326-331. 